\title{
Monitoring for depth of anesthesia: a review
}

\author{
Amornyotin Somchai \\ Department of Anesthesiology and Siriraj GI Endoscopy Center, Faculty of Medicine Siriraj Hospital, Mahidol University, \\ Bangkok, Thailand. \\ Correspondence: Somchai Amornyotin. Address: Department of Anesthesiology and Siriraj GI Endoscopy Center, \\ Faculty of Medicine Siriraj Hospital, Mahidol University, Bangkok 10700, Thailand. Telephone: 662-419-7990. Fax: \\ 662-411-3256. Email: sisam@mahidol.ac.th.
}

Received: May 27, 2012

Accepted: July 16, 2012

URL: http://dx.doi.org/10.5430/jbgc.v2n2p119

Published: December 1, 2012

DOI : $10.5430 / j b g c . v 2 n 2 p 119$

\section{Abstract}

Monitoring depth of anesthesia is a newer advance in the monitoring of anesthesia. Accurate assessment of the depth of anesthesia contributes to tailoring drug administration to the individual patient. Its increasing use may help to prevent awareness or excessive anesthetic depth and to improve the patients' outcomes. Awareness experiences frighten the patients and can leave a lifetime of residual emotional and psychological problems. To date, no monitoring system has been found to measure the depth of anesthesia reliably for all patients and all anesthetic agents. In this review, the author critically analyzes the use of a number of the depth of anesthesia monitors including the traditional techniques and the modern techniques.

\section{Key words}

Monitoring, Depth of anesthesia, Sedation

\section{Introduction}

Many surgical procedures would not be possible without anesthesia or sedation. The goals of anesthesia or sedation are a reversible loss of consciousness with a lack of movement, a lack of awareness or recall, and unresponsiveness to painful stimuli. Inadequate anesthesia or sedation may lead to intraoperative awareness with recall or to prolonged recovery and increased risk of postoperative complications for the patients. Important signs of inadequate anesthesia, signs which develop in response to stress or painful stimuli, are patient movement, increased breathing or blood pressure and increased heart rate ${ }^{[1]}$. Failure to adjust the anesthetic requirements to individual variations in patient drug requirements and to the intensity of pain stimulation during surgical procedures will also lead to over dosage or under dosage with anesthesia or sedation.

\section{Depth of sedation/ anesthesia}

Minimal sedation (anxiolysis) is a drug-induced state during which patients respond normally to verbal commands. Although cognitive function and physical coordination may be impaired, airway reflexes and ventilatory and cardiovascular functions are unaffected. 
Moderate sedation (conscious sedation) is a drug-induced depression of consciousness during which patients respond purposefully to verbal commands, either alone or accompanied by light tactile stimulation. No interventions are required to maintain a patent airway, and spontaneous ventilation is adequate. Cardiovascular function is usually maintained.

Deep sedation is a drug-induced depression of consciousness during which patients can not be easily aroused but respond purposefully following repeated or painful stimulation. The ability to independently maintain ventilatory function may be impaired. Patients may require assistance in maintaining a patent airway, and spontaneous ventilation may be inadequate. Cardiovascular function is usually maintained.

General anesthesia is a drug-induced loss of consciousness during which patients are not arousable, even by painful stimulation. The ability to independently maintain ventilatory function is often impaired. Patients often require assistance in maintaining a patent airway, and positive pressure ventilation may be required because of depressed spontaneous ventilation or drug-induced depression of neuromuscular function. Cardiovascular function may be impaired.

\section{Monitoring for depth of anesthesia}

The transition from a state of wakefulness to a state of general anesthesia is accompanied by profound changes in the brain's spontaneous electrical activity recorded from electrodes placed on the scalp (electroencephalogram or EEG). The clinical monitoring is simple and is commonly used by the variety of physicians. Only the advances in computer hardware and signal processing algorithms have enabled the processing of EEG signals.

\section{Clinical monitoring}

Continuous monitoring of patient undergoing anesthesia or sedation is very important for ensuring the safety of the procedure, and is of paramount importance in order to obtain a correct level of sedation in surgical patients. The physicians need to monitor and evaluate the patients' status and the depth of anesthesia or sedation throughout the procedure. Clinical scoring systems are simple and inexpensive. In addition, clinical observation of the sedated patients can provide an early warning for potentially dangerous problems. The clinical monitoring used to assess intraoperative consciousness are checking for movement, response to verbal command, eyelash reflex, pupillary responses, tearing and pattern of respiration.

\subsection{Clinical signs}

The most commonly used scoring system is Evans's score ${ }^{[2]}$. This score assesses autonomic activity related to systolic blood pressure, heart rate, sweating and tears. This system is simple and not requiring specialized equipment. However, these parameters are not specific and the scores can vary widely among individuals. ASA task force members on practice advisory for intraoperative awareness and brain function monitoring have been recommended physicians should be used these clinical signs to assess intraoperative consciousness ${ }^{[3]}$. Additionally, conventional monitoring systems including electrocardiogram, noninvasive blood pressure, capnography and end tidal anesthetic analyzer are valuable and should be used to help assessment of these clinical signs.

\subsection{Skin conductance}

Measuring skin resistance level and changes in the resistance of the skin is a simple and noninvasive method for evaluating the sympathetic nerve activity. The measurement of skin conductance is a quantification of the clinical sign of sweat production. Skin conductance is initially low and increases as anesthetic depth is increased. There has a correlation between electrical skin impedance, predicted plasma concentrations of propofol and the MOAAS scale ${ }^{[4]}$. The individual variability of the measurement values constitutes a problem in the interpretation of skin resistance measurements. In addition, several factors affecting sweating can reduce the accuracy of this monitoring. 


\subsection{I solated forearm technique}

Isolated forearm technique is a method detecting awareness during clinical practice. The tourniquet is applied to the patient's upper arm before administration of the muscle relaxant, and is inflated above systolic blood pressure to exclude its effect. Movement of the arm indicated wakefulness or light anesthesia, although not necessarily explicit awareness. However, the incidence of movement with this technique can vary with the choice of anesthetic drugs ${ }^{[5]}$. Other limitations of this technique are the limited time available before the patients are unable to move their arms, level of sedation/anesthesia needed to prevent the movement of patient's arm, and the nonspecific response may be misinterpreted.

\subsection{Heart rate variability}

Clinically, the beat to beat variability of heart rate may provide information which would be useful for monitoring depth of anesthesia. Three components of the heart rate variability are low, medium and high frequency fluctuations. Heart rate increases during inspiration and decreases during expiration through the parasympathetic reflex. This is called as the respiratory sinus arrhythmia (RSA). The reduction of the RSA is observed during anesthesia together with increase during recovery. Some monitors use the heart rate variability at respiratory frequency or RSA as a method assessing anesthetic depth ${ }^{[6]}$. However, the vagal tone depends on an intact of autonomic nervous system and healthy myocardial conducting system. Additionally, several factors influencing the heart rate variability in the perioperative setting are conduction abnormalities, autonomic neuropathy and sepsis as well as some medications such as beta-blockers and atropine.

\subsection{Ramsay scale}

The Ramsay scale was developed in 1970 in order to promote adequate sedation in intensive care units. It is internationally one of the most frequently cited sedation assessment tools. The Ramsay scale mainly involves a positive approach to the patient, designed to cause minimal disturbance to sleep. The level of sedation in mechanically ventilated patients is most often assessed with the Ramsay scale. This sedation scale divides into six score responses ${ }^{[7]}$.

1 Anxious, agitated, restless

2 Cooperative, tranquil, oriented

3 Drowsy, response to verbal command

4 Asleep, brisk response to light glabellar tap and loud auditory stimulus

5 Asleep, sluggish response to light glabellar tap and loud auditory stimulus

6 No response to stimulus

To date, the reliability of the Ramsay scale remains controversial. Many studies show that there are insufficient evidences to support the reliability of the Ramsay sedation scale as a measure of sedation assessment ${ }^{[8,9]}$. In contrast, several studies demonstrate that the inter-observer reliability of the level of sedation measurements, performed in daily clinical practice within a large team of physicians, proved to be almost perfect ${ }^{[10,11]}$. However, the Ramsay scale is largely outdated and has been superseded by more appropriate, practical scoring tools.

\subsection{Modified observer assessment of alertness/ sedation scale MOAA/ S)}

The Modified Observer Assessment of Alertness/Sedation scale (MOAA/S) is a six-point scale ranging from 5 to 0 . It entails a positive action that involves eliciting a response to increasingly intense stimuli ${ }^{[12]}$. Patients are considered to have loss of consciousness at the transition between level 3 and level 2.

5 Responds readily to name spoken in normal tone

4 Lethargic response to name spoken in normal tone 
3 Response only after name is called loudly and/or repeatedly

2 Response only after mild prodding or shaking

1 Response only after painful trapezius squeeze

0 No response after painful trapezius squeeze

To date, the author also uses the MOAA/S for sedation for various gastrointestinal endoscopic procedures ${ }^{\text {[13-15]. }}$ Generally, the MOAA/S and the Ramsay scale are not interchangeable with the definitions of the levels of sedation. There is evidence of a correlation between the MOAA/S score and the Bispectral (BIS) measurement in several studies ${ }^{[16]}$. The monitoring of stress response during surgery is important, because prolonged surgical stress can lead to increased morbidity and delayed postoperative recovery ${ }^{[17]}$. An appropriate depth of sedation is routinely adjusted by titration of sedative concentration. Generally, the changes in heart rate and arterial blood pressure were used as signs of increased nociception during sedation but their specificity and sensitivity is not very high ${ }^{[18]}$.

\section{Anesthetic depth monitoring tools}

Because of clinical scoring systems are often inadequate in evaluating the patient's level of consciousness, many instrumental tools of anesthetic depth monitoring have been proposed, and particularly the direct evaluation of the central nervous system actions of anesthetic drugs. The monitor that would enable objective, reproducible and continuous measurement of anesthetic depth has lead to the development of EEG or AEP (auditory evoked potentials) based monitors $^{[1,19]}$.

\section{Factors that interfere EEG measurements}

The quality of EEG records is mainly influenced by internal or external sources of electromagnetic waves. Numerous sources of interference can mislead EEG measurements. The common sources of interference are the electrical activity of head muscles ${ }^{[20]}$, cardiac pacemaker ${ }^{[21]}$, hot air blanket systems ${ }^{[22]}$ and the electrocoagulation needles ${ }^{[23]}$. The EEG activity is also influenced by anesthetic agents. However, ketamine does not change the BIS index even when patients are unconscious $^{[24]}$. Ketamine has no effects on AEP ${ }^{[25]}$. The effects of nitrous oxide on EEG or BIS value are varied and therefore unpredictable ${ }^{[24,26,27]}$. So, the current EEG or AEP-based anesthetic monitoring devices are not able to reliably assess the patient's depth of anesthesia when ketamine or nitrous oxide is used.

Physiological conditions, such as age ${ }^{[28]}$, race ${ }^{[29]}$, gender ${ }^{[30]}$, low body temperature ${ }^{[31]}$, acid-base imbalances ${ }^{[32]}$, low blood glucose ${ }^{[33]}$ or cerebral ischemia ${ }^{[26]}$ also have a significant effect on patient can influence the EEG. The changes in the patient's age or general health may require adjustment of anesthetic agents. This variability in drug concentration is caused by variability of physiological effects of drugs on the differences in pharmacodynamics and pharmacokinetics. Neuromuscular blocking agents have the effects on muscle electrical activity and indirectly on the signal quality of EEG measurement ${ }^{[34]}$. AEP are the responses of the auditory pathway to sound stimuli. An AEP is calculated by repeatedly applying an auditory stimulus to the patient and averaging EEG periods that immediately follow each stimulus ${ }^{[6]}$. Compared to the raw EEG, AEP is less sensitive to artifacts. However, there still have no direct measure of consciousness available in clinical practice and thus no gold standard against which to test EEG or AEP derived indices of anesthetic depth $^{[35]}$. 


\section{Commercial monitoring tools}

The anesthetic depth monitoring technology is promising and used widely, nevertheless to date no health authority has so far recommended that such monitors should be compulsory during general anesthesia or sedation, but should be considered only on an individual basis. To date, there have many commercial monitoring tools.

\subsection{Bispectral I ndex Monitor}

The Bispectral index (BIS) was first introduced in 1992 by Aspect Medical Systems. The main component of the BIS monitor is the bispectral analysis, which evaluates the phase relations from a single channel EEG signal measured from the patient's forehead. Recently, the BIS is developed to ease EEG interpretation. It gives the level of sedation as a constant read-out from the device after analysis of single channel EEG findings. The BIS has been reported to be more precise in measurement of the depth of anesthesia. Among instrumental tools for anesthetic depth monitoring, BIS monitor is now widely used due to its reliability and applicability. In addition, the BIS monitoring is a noninvasive method of assessing patient's level of consciousness. The BIS scale ranges from 0 to 100 (0, no cortical activity or coma; 40-60, unconscious, general anesthesia; 60-70, deep sedation with low probability of explicit recall; 70-95, light to moderate sedation; 95-100, awake). BIS monitor has been employed to monitor the depth of anesthesia ${ }^{[36]}$ and sedation in intensive care unit patients ${ }^{[37]}$. Additionally, BIS monitor is also the anesthetic depth monitoring that has been routinely used in pediatric anesthesia $^{[38,39]}$.

Generally, the BIS or alternative EEG-based monitoring of anesthetic depth might be useful in preventing oversedation and in reducing propofol dosages during the maintenance phase of the procedure ${ }^{[40]}$. However, the previous observational study of BIS during nurse-administered propofol sedation (NAPS) found that the BIS scores lagged substantially behind actual sedation scores during both induction of sedation and recovery ${ }^{[4]}$. Additionally, several studies also demonstrated that BIS did not lead to reduction in mean propofol dose or recovery time when used as an adjunct to NAPS for colonoscopy, or when used as the primary target for sedation. No clinically important role for BIS monitoring as an adjunct to NAPS has yet been established ${ }^{[42,43]}$.

\subsection{Narcotrend monitor}

The Narcotrend monitor is produced by Monitor Technik, Hannover Medical School and was introduced in the year 2000. It performs a computerized analysis of the raw EEG. Narcotrend monitor has two recording modes; the one channel mode as the standard for the assessment of the depth of hypnosis during anesthesia or sedation, and the two channel mode for comparison of signals from the two hemispheres of the brain. After accounting for the artifacts, a multivariate statistical algorithm is used for analysis which results in a six-stage classification from A (awake) to F (general anesthesia/coma) and 14 substages ${ }^{[44]}$. Additionally, the Narcotrend would have less problems with EMG interference than the BIS monitor ${ }^{[45]}$. This is most likely due to the fact that the Narcotrend modulates the index value with artifact surrogate analysis. The Narcotrend-guided sedation demonstrated lower hemodynamic changes and fewer complications compared with the clinical assessment-guided sedation for endoscopic retrograde cholangiopancreatography procedure. However, the Narcotrend and clinical assessment-guided deep sedation showed comparable propofol dosage and recovery time ${ }^{[46]}$.

\subsection{AEP Monitor/ 2}

The first commercial monitor based on AEP was introduced by Danmeter in 2001. After further research, the same company introduced the new version of the monitor. The AEP Monitor/2 (Danmeter A/S, Odense, Denmark) features an auditory evoked potential (AEP) and EEG-derived hybrid index of the patient's hypnotic state. This monitor uses autoregressive models with exogenous input (ARX) to detect the AEP. The ARX was used because the method enables fast responses of the monitor ${ }^{[47]}$. Like other successful monitors the new version of the index also calculates the AEP-ARX-Index (AAI index), which is a dimensionless number. The AAI index can be displayed on two scales; either from 0 to 100 , or from 0 to 60 . 
Because the EMG is propagated in the same frequency band, the AAI can be influenced by the EMG artifacts. The decision how the AAI is constructed from AEP and EEG analyses is made by the weighting function, which is based on the signal to noise ratio. All of the above parameters must be monitored simultaneously in order to ensure optimal sedation/anesthesia of the patient during general anesthesia ${ }^{[48,49]}$. Several studies have compared AAI with BIS and revealed that the AAI was more sensitive in monitoring depth of anesthesia and in predicting recovery to consciousness ${ }^{[50,51]}$.

\subsection{PSA 4000 Monitor}

The Patient State Analyzer 4000 (PSA) was developed by the Physiometrix, North Billerica, MA and launched in 2001 in the USA. The PSA monitor calculates the value of the index from four EEG channels. The acquired signals are pre-processed and an artifact removal algorithm is applied. The Patient State Index (PSI) uses a set of features that best describe the variances, which are related to the EEG. The development of the PSI algorithm was based on three databases of EEG records, which were used for development of artifact detection and removal algorithms, classification algorithms and finally a third database was used for calibrating the index ${ }^{[52]}$. The PSI is a dimensionless number from 100 (awake) to 0 (isoelectricity).

\subsection{Cerebral State Monitor}

The Cerebral State Monitor (CSM) was introduced by the Danmeter Company in 2004.The ability of CSM for separation of consciousness and unconsciousness was comparable to other commercially available EEG-based devices ${ }^{[53]}$. Although, CSM has a simpler algorithm in comparison to Narcotrend and PSI, it is the slowest to respond to a change in sedation. The study of Hoymork et al. showed that the CSM was a satisfactory alternative to BIS for monitoring hypnotic effect in $87 \%$ of non-paralyzed patients. In 13\% of the patients, CSI displayed values indicating an awaked state despite clinical sleep, all correctly identified with the BIS. However, their study was done with the very first version of the CSM, while the BIS monitor has undergone several revisions ${ }^{[54]}$.

\subsection{Entropy Module}

Another way of using EEG data is for the calculation of entropy, which is a measure of the irregularity, complexity or predictability characteristics of the data ${ }^{[55]}$. The Entropy Module was introduced in 2003 by the Datex-Ohmeda Company. The increasing depth of anesthesia causes increase in regularity of the EEG, which can then be inferred by the entropy and used to estimate the depth of anesthesia.

Two features of this monitor are state entropy (SE) and response entropy (RE). Both are dimensionless numbers between 91-0 and 100-0, respectively. The SE includes information only from EEG, and the RE includes the EMG activity and can be therefore used as a surrogate parameter. The Entropy monitor is also the anesthetic depth monitor that has been routinely used in pediatric anesthesia ${ }^{[38,39]}$.

\section{The response time of DGA monitors}

One of the most important parameters of the anesthetic depth monitor is its response time to a rapid change in the level of sedation/anesthesia. The response time is between 30-100 seconds for the transition between EEG suppression and the awaked state for BIS, Narcotrend and CSM ${ }^{[56]}$. However, the response time is not constant and is dependent upon the depth of anesthesia. The time delays of the tested indices may limit their value in prevention of recall of intraoperative events. Furthermore, different latencies for decreasing and increasing values may indicate a limitation of these monitors for the pharmacodynamic studies ${ }^{[57]}$. 


\section{Conclusions}

One of the objectives of anesthesia is to ensure adequate depth of anesthesia to prevent the patients' awareness. All available monitors are no predictors whether the depth of anesthesia is sufficient for the painful surgical stimulus. The anesthetic personnel must consider any technique for monitoring of the depth of anesthesia as an individual help in improving care for their patients. Recent advances in the introduction of EEG-based monitors have made important contributions towards understanding of the fundamental changes in brain activity brought about by anesthetic agents. The development of these monitors, which directly measures the state of consciousness, would also enable a safe and cost-effective anesthetic procedure.

Table. Comparison of anesthetic depth monitors

\begin{tabular}{|c|c|c|c|c|c|c|}
\hline & BIS & Narcotrend & $\begin{array}{l}\text { AEP } \\
\text { Monitor/2 }\end{array}$ & PSA 4000 & CSM & Entropy \\
\hline First introduced & 1992 & 2000 & 2001 & 2001 & 2004 & 2003 \\
\hline Produced by & $\begin{array}{l}\text { Aspect } \\
\text { Medical } \\
\text { System }\end{array}$ & Monitor Technik & Danmeter & Physiometrix & Danmeter & $\begin{array}{l}\text { Datex-Oh } \\
\text { meda }\end{array}$ \\
\hline \multicolumn{7}{|l|}{ Time delay } \\
\hline $\begin{array}{l}\text { Awake to deep } \\
\text { anesthesia }\end{array}$ & $61 \mathrm{sec}$ & $26 \mathrm{sec}$ & No data & No data & $55 \mathrm{sec}$ & No data \\
\hline $\begin{array}{l}\text { Deep anesthesia to } \\
\text { awake }\end{array}$ & $63 \mathrm{sec}$ & $90 \mathrm{sec}$ & No data & No data & $106 \mathrm{sec}$ & No data \\
\hline $\begin{array}{l}\text { Electromagnetic } \\
\text { interference }\end{array}$ & Moderate & Moderate & No data & No data & Moderate & High \\
\hline $\begin{array}{l}\text { Correlation with } \\
\text { clinical signs }\end{array}$ & Yes & Yes & Yes & $\begin{array}{l}\text { Needed more } \\
\text { studies }\end{array}$ & Yes & Yes \\
\hline
\end{tabular}

\section{References}

[1] Myles PS. Prevention of awareness during anesthesia. Best Pract Res Clin Anesthesiol. 2007; 21: 345-355. http://dx.doi.org/10.1016/j.bpa.2007.04.004

[2] Evans JM, Davies WL. Monitoring anesthesia. Clin Anesth. 1984; 2: 243-262.

[3] Anonymous. Practice advisory for intraoperative awareness and brain function monitoring. A report by the American Society of Anesthesiologists Task Force on intraoperative awareness. Anesthesiology. 2006; 104: 847-864. PMid:16571982

[4] Winterhaltera M, Munted S, Taschenbreckerc P, et al. Skin impedance correlates to sedation grade, plasma propofol concentrations and bispectral index during a target-controlled infusion of propofol. Eur J Anaesthesiol. 2009; 26: 589-596. PMid:19455042 http://dx.doi.org/10.1097/EJA.0b013e328329b149

[5] Russell IF. Comparison of wakefulness with two anesthetic regimens: total IV balanced anesthesia. Br J Anaesth.1986; 58: 965. PMid:3756056 http://dx.doi.org/10.1093/bja/58.9.965

[6] Sinha PK, Koshy T. Monitoring devices for measuring the depth of anesthesia-an overview. Indian J Anesth. 2007; 51: 365-381.

[7] Ramsay MA, Savege TM, Simpson BR, Goodwin R. Controlled sedation with alphaxalone-alphadolone. Br Med J. 1974 ; 2: 656-659. PMid:4835444 http://dx.doi.org/10.1136/bmj.2.5920.656

[8] Olson DW, Lynn M, Thoyre SM, Graffagnino C. The limited reliability of the Ramsay scale. Neurocritical Care. $2007 ;$ 7: $227-231$. PMid:17896083 http://dx.doi.org/10.1007/s12028-007-0069-x

[9] Nemethy M, Paroli L, Williams-Russo P, et al. Assessing sedation with regional anesthesia: inter-rater agreement on a Modified Wilson Sedation scale. Anesth Analg. 2002; 94: 725-728.

[10] Van Dishoeck AM, Van der Hooft T, Simoons ML, et al. Reliable assessment of sedation level in routine clinical practice by adding an instruction to the Ramsay scale. Eur J Cardiovasc Nurs. 2009; 8: 125-128. PMid:19056319 http://dx.doi.org/10.1016/j.ejcnurse.2008.10.004

[11] Mottahedian TE, Tadrissi SD, Mohammad YA, Ebadi A, Mirhashemi S. Validity and reliability of Ramsay sedation scale in intensive care unit adult patients. Iranian J Crit Care Nursing. 2010; 3: 39-44. 
[12] Chernik DA, Gillings D, Laine H, et al. Validity and reliability of the observer's assessment of alertness/sedation scale: study with intravenous midazolam. J Clin Psychopharmacol. 1990; 10: 244-251. PMid:2286697

[13] Amornyotin S, Srikureja W, Pausawasdi N, Prakanrattana U, Kachintorn U. Intravenous sedation for gastrointestinal endoscopy in very elderly patients of Thailand. Asian Biomed. 2011; 5: 485-491.

[14] Amornyotin S, Kachintorn U, Chalayonnawin W, Kongphlay S. Propofol-based deep sedation for endoscopic retrograde cholangiopancreatography procedure in sick elderly patients in a developing country. Ther Clin Risk Manag. 2011; 7: $251-255$. PMid:21753887 http://dx.doi.org/10.2147/TCRM.S21519

[15] Amornyotin S, Kongphlay S. Esophagogastroduodenoscopy procedure in sick pediatric patients: a comparison between deep sedation and general anesthesia technique. J Anesth Clin Res. 2012; 3: 185.

[16] Punjasawadwong Y, Boonjeungmonkol N, Phongchiewboon A. Bispectral index for improving anesthetic delivery and post-operative recovery. Cochrane Database Syst Rev. 2007; 4: CD003843. PMid:17943802

[17] Hahnenkamp K, Herroeder S, Hollmann MW. Regional anesthesia, local anesthetics and the surgical stress response. Best Pract Res Clin Anesthesiol. 2004; 18: 509-527. http://dx.doi.org/10.1016/j.bpa.2004.01.004

[18] Luginbuhl M, Ypparila-WoltersH, Rufenacht M, Petersen-Felix S, Korhonen I. Heart rate variability does not discriminate between different levels of hemodynamic responsiveness during surgical anesthesia. $\mathrm{Br} \mathrm{J}$ Anesth. 2007; 98: 728-736. PMid:17468493 http://dx.doi.org/10.1093/bja/aem085

[19] Bruhn J, Myles PS, Sneyd R, Struys MM. Depth of anesthesia monitoring: What's available, what's validated and what's next? Br J Anesth. 2006; 97: 85-94. PMid:16751211 http://dx.doi.org/10.1093/bja/ael120

[20] Renna M, Wigmore T, Mofeez A, Gillbe C. Biasing effect of the electromyogram on BIS: a controlled study during high-dose fentanyl induction. J Clin Monit Comput. 2002; 17: 377-381. PMid:12885182 http://dx.doi.org/10.1023/A:1024210405543

[21] Vretzakis G, Dragoumanis C, Ferdi H, Papagiannopoulou P. Influence of an external pacemaker on bispectral index. Eur J Anaesthesiol. 2005; 22: 70-72. PMid:15816579

[22] Hemmerling TM, Fortier JD. Falsely increased bispectral index values in a series of patients undergoing cardiac surgery using forced-air-warming therapy of the head. Anesth Analg. 2002; 95: 322-323. PMid:12145044

[23] Gomez LM, Anadon MP, Salvador M, Aldaz M, Raigoso O, Senandez MJ. Increase of bispectral index values due to electrical interference by the RF 2000 radiofrequency generator during ablation of hepatic metastases. Rev Esp Anestesiol Reanim. 2002; 49: 218-219. PMid:14606384

[24] Hirota K. Special cases: ketamine, nitrous oxide and xenon. Best Pract Res Clin Anesthesiol. 2006; 20: 69-79. http://dx.doi.org/10.1016/j.bpa.2005.08.014

[25] Vereecke HE, Struys MM, Mortier EP. A comparison of bispectral index and ARX-derived auditory evoked potential index in measuring the clinical interaction between ketamine and propofol anesthesia. Anaesthesia. 2003; 58: 957-961. PMid:12969037 http://dx.doi.org/10.1046/j.1365-2044.2003.03403.x

[26] Hirota K, Kubota T, Ishihara H, Matsuki A. The effects of nitrous oxide and ketamine on the bispectral index and 95\% spectral edge frequency during propofol-fentanyl anesthesia. Eur J Anaesthesiol. 1999; 16: 779-783. PMid:10713872

[27] Puri GO. Paradoxical changes in bispectral index during nitrous oxide administration. Br J Anesth. 2001; 86: 141-142. PMid:11575394 http://dx.doi.org/10.1093/bja/86.1.141

[28] Schultz A, Grouven U, Zander I, Beger FA, Siedenberg M, Schultz B. Age-related effects in the EEG during propofol anesthesia. Acta Anaesthesiol Scand. 2004; 48: 27-34. PMid:14674970 http://dx.doi.org/10.1111/j.1399-6576.2004.00258.x

[29] Ortolani O, Conti A, Ngumi ZW, et al. Ethnic differences in propofol and fentanyl response: a comparison among Caucasians, Kenyan Africans and Brazilians. Eur J Anaesthesiol. 2004; 21: 314-319.

[30] Kodaka M, Johansen JW, Sebel PS. The influence of gender on loss of consciousness with sevoflurane or propofol. Anesth Analg. 2005; 101: 377-381. http://dx.doi.org/10.1213/01.ANE.0000154534.71371.4F

[31] Schmidlin D, Hager P, Schmid ER. Monitoring level of sedation with bispectral EEG analysis: comparison between hypothermic and normothermic cardiopulmonary bypass. Br J Anaesth. 2001; 86: 769-776. PMid:11573582 http://dx.doi.org/10.1093/bja/86.6.769

[32] Turnbull D, Furlonger A, Andrzejowski J. The influence of changes in end-tidal carbondioxide upon the Bispectral index. Anaesthesia. 2008; 63: 458-462. PMid:18412642 http://dx.doi.org/10.1111/j.1365-2044.2007.05399.x

[33] Vivien B, Langeron O, Riou B. Increase in bispectral index (BIS) while correcting a severe hypoglycemia. Anesth Analg. 2002; 95: 1824-1825. http://dx.doi.org/10.1097/00000539-200212000-00082

[34] Messner M, Beese U, Romstock J, Dinkel M, Tschaikowsky K. The bispectral index declines during neuromuscular block in fully awake persons. Anesth Analg. 2003; 97: 488-491. http://dx.doi.org/10.1213/01.ANE.0000072741.78244.C0

[35] Palanca BJ, Mashour GA, Avidan MS. Processed electroencephalogram in depth of anesthesia monitoring. Curr Opin Anesthesiol. 2009; 22: 553-559. PMid:19652597 http://dx.doi.org/10.1097/ACO.0b013e3283304032

[36] Johansen JW, Sebel PS. Development and clinical application of electroencephalographic bispectrum monitoring. Anesthesiology. 2000; 93: 1336-1344. PMid:11046224 http://dx.doi.org/10.1097/00000542-200011000-00029

[37] Consales G, Chelazzi C, Rinaldi S, De Gaudio AR. Bispectral index compared to Ramsay score for sedation monitoring in intensive care units. Minerva Anestesiol. 2006; 72: 329-336. PMid:16675941 
[38] Powers KS, Nazarian EB, Tapyrik SA, et al. Bispectral index as a guide for titration of propofol during procedural sedation among children. Pediatrics. 2005; 115: 1666-1674. PMid:15930231 http://dx.doi.org/10.1542/peds.2004-1979

[39] Klockars JG, Hiller A, Ranta S, et al. Spectral entropy as a measure of hypnosis in children. Anesthesiology. 2006; $104: 708-717$. PMid:16571966 http://dx.doi.org/10.1097/00000542-200604000-00015

[40] Wehrmann T, Grotkamp J, Stergiou N, et al. Electroencephalogram monitoring facilitates sedation with propofol for routine ERCP: a randomized controlled trial. Gastrointest Endosc. 2002; 56:817-824. http://dx.doi.org/10.1016/S0016-5107(02)70353-2

[41] Chen SC, Rex DK. An initial investigation of bispectral monitoring as an adjunct to nurse-administered propofol sedation for colonoscopy. Am J Gastroenterol. 2004; 99: 1081-1086. PMid:15180729 http://dx.doi.org/10.1111/j.1572-0241.2004.03279.x

[42] Drake LM, Chen SC, Rex DK. Efficacy of Bispectral monitoring as an adjunct to nurse-administered propofol sedation for colonoscopy: a randomized controlled trial. Am J Gastroenterol. 2006; 101: 2003-2007. PMid:16968506 http://dx.doi.org/10.1111/j.1572-0241.2006.00806.x

[43] DeWitt JM. Bispectral index monitoring for nurse-administered propofol sedation during upper endoscopic ultrasound: a prospective, randomized controlled trial. Dig Dis Sci. 2008; 53: 2739-2745. PMid:18274899 http://dx.doi.org/10.1007/s10620-008-0198-x

[44] Kreuer S, Biedler A, Larsen R, Altmann S, Wilhelm W. Narcotrend monitoring allows faster emergence and a reduction of drug consumption in propofol-remifentanil anesthesia. Anesthesiology. 2003; 99: 34-41. PMid:12826839 http://dx.doi.org/10.1097/00000542-200307000-00009

[45] Panousis P, Heller AR, Burghardt M, Bleyl JU, Koch T. The effects ofelectromyographic activity on the accuracy of the Narcotrend monitor compared with the Bispectral index during combined anesthesia. Anaesthesia. 2007; 62: 868-874. PMid:17697211 http://dx.doi.org/10.1111/j.1365-2044.2007.05145.x

[46] Amornyotin S, Chalayonnawin W, Kongphlay S. Deep sedation for endoscopic retrograde cholangiopancreatography: a comparison between clinical assessment and Narcotrend ${ }^{\mathrm{TM}}$ monitoring. Med Devices: Evid Res. 2011; 4: 43-49. PMid:22915929 http://dx.doi.org/10.2147/MDER.S17236

[47] Weber F, Zimmermann M, Bein T. The impact of acoustic stimulation on the AEP Monitor/2 derived composite auditory evoked potential index under awake and anesthetized conditions. Anesth Analg. 2005; 101: 435-439. http://dx.doi.org/10.1213/01.ANE.0000158470.34024.EF

[48] Plourde G. Auditory evoked potentials. Best Pract Res Clin Anesthesiol. 2006; 20: 129-139. http://dx.doi.org/10.1016/j.bpa.2005.07.012

[49] Horn B, Pilge S, Kochs EF, Stockmanns G, Hock A, Schneider G. A combination of electroencephalogram and auditory evoked potentials separates different levels of anesthesia in volunteers. Anesth Analg. 2009; 108: 1512-1521. http://dx.doi.org/10.1213/ane.0b013e3181a04d4c

[50] Gajraj RJ, Doi M, Mantzaridis H, Kenny GNC. Comparison of bispectral EEG analysis and auditory evoked potentials for monitoring depth of anesthesia during propofol anesthesia. Br J Anaesth. 1999; 82: 672-678. PMid:10536541 http://dx.doi.org/10.1093/bja/82.5.672

[51] Nishiyama T, Hanaoka K. The A-line ARX index may be a more sensitive detector of arousal than the bispectral index during propofol-fentanyl-nitrous oxide anesthesia: a preliminary investigation. Can J Anesth. 2004; 51: 539-544. PMid:15197114 http://dx.doi.org/10.1007/BF03018394

[52] Drover DR, Lemmens HJ, Pierce ET, et al. Patient state index. Anesthesiology. 2002; 97: 82-89. PMid:12131107 http://dx.doi.org/10.1097/00000542-200207000-00012

[53] Pilge S, Blum J, Kochs EF, Schoniger SA, Kreuzer M, Schneider G. Does the Cerebral State Index separate consciousness from unconsciousness? Anesth Analg. 2011; 113: 1403-1410. http://dx.doi.org/10.1213/ANE.0b013e31823007cd

[54] Hoymork SC, Hval K, Jensen EW, Raeder J. Can the Cerebral State Monitor replace the Bispectral index in monitoring hypnotic effect during propofol/remifentanil anesthesia? Acta Anaesthesiol Scand. 2007; 51: 210-216. PMid:17330331 http://dx.doi.org/10.1111/j.1399-6576.2006.01213.x

[55] Bruhn J, Lehmann LE, Ropcke H, et al. Shannon entropy applied to the measurement of the electroencephalographic effects of desflurane. Anesthesiology. 2001; 95: 30-55. PMid:11465580 http://dx.doi.org/10.1097/00000542-200107000-00010

[56] Zanner R, Pilge S, Kochs EF, Kreuzer M, Schneider G. Time delay ofelectroencephalogram index calculation: analysis of cerebral state, bispectral, and Narcotrend indices using perioperatively recorded electroencephalographic signals. Br J Anaesth. 2009 ; 103: 394-399. PMid:19648154 http://dx.doi.org/10.1093/bja/aep198

[57] Pilge S, Zanner R, Schneider G, et al. Time delay of index calculation: analysis of cerebral state, bispectral, and Narcotrend indices. Anesthesiology. 2006; 104: 488-494. PMid:16508396 http://dx.doi.org/10.1097/00000542-200603000-00016 